\title{
Improving The Engineering Properties of The Gypseous Soil Using Dynamic Compaction Method
}

\author{
Prof. Dr. Mohamad T. Al-Layla \\ Civil Engineering Department \\ University of Mosul / Iraq \\ tayebal_layla@yahoo.com
}

\author{
Dr.Qutayba Nazar Al-Saffar \\ Civil Engineering Department \\ University of Mosul / Iraq \\ qutayba_alsaffar@yahoo.com
}

\begin{abstract}
The aim of this study is to improve the engineering properties of gypseous soils, located in Bajii city $(160 \mathrm{~km}$ South of Mosul city) using the Field Dynamic Compaction (FDC) techniques. This technique consist of dropping a reinforced concrete block (1x1x1 m) weighing (2.4 Tons) from different heights on a gypseous soil of thickness varaing from $(0.5-2.4 \mathrm{~m})$ and underlain by sub-base material.

The effect of FDC on the gypseous soil was investigated using SPT in the field and using the conventional laboratory apparatus in the laboratory tests.

The results showed that the unit weight increased (14-32\%) for one drop of the weight. The effective angle of internal friction $\left(\phi^{-}\right)$increased from $(320)$ to about $\left(36^{\circ}\right)$ while the compression index $(\mathrm{Cc})$ decreased from $(0.24)$ to about $(0.07-0.1)$.

The results of this study indicated that about $(60-80 \%)$ of the improvement was achieved from the first blow in loose to meduime soils. However about $(25 \%)$ of the improvement was reached in dense soils.

The FDC is a promising technique for improving the engineering properties of gypseous soil and overcome most of the gypseous soil problems.

Key words: Dynamic compaction, Gypseous soil, Soil Improving and SPT-Test

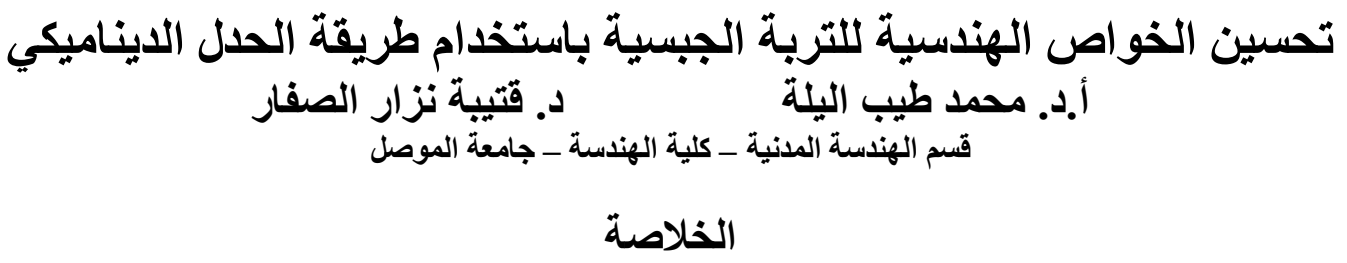

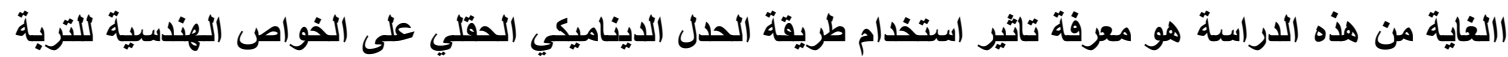

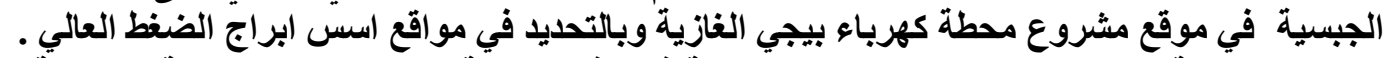

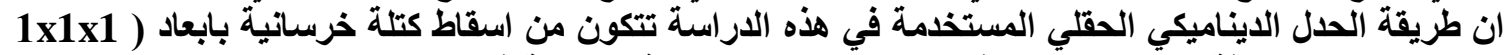

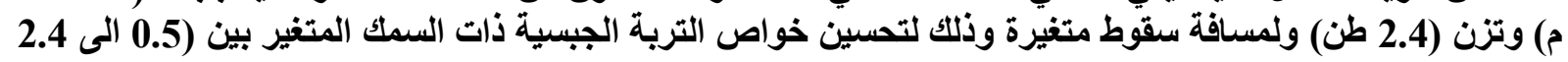

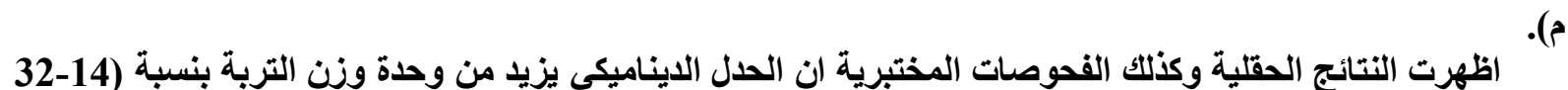



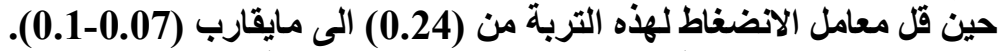

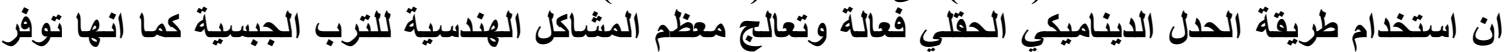
الجها والكلقة وبالتالي من الممكن استخدامها في مختلف المشاريع المقامة على التربة الجبسية.
\end{abstract}




\section{Introduction}

It is a fact that soils are extremely complicated engineering materials whose constitutive response depends on many factors, including soil type, density, water content, structure, particles size, drainage conditions, duration of loading, stress history, confining pressure, and stress path $[1,14]$.

The gypseous soil forms approximately (27-36) percentage of Iraqi soils and this type of soil is the source of many problems in the engineering structures which are built on it.

Soil improvement techniques fall under several categories, the improvement can takes place by densification, reinforcement, removal and replacement and physico-chemical alterations. Each category has its specific application in which it is more competitive than the others. Densification in general is the most commonly method used because it is relatively cheaper than other techniques especially when large area of construction is to be improved [3,12].

Dynamic compaction is one of the soil improvement method that is used to improve the soil properties to support buildings, roadways, and other heavy constructions[1,3]. The dynamic compaction method was used to save cost and time relative to the other methods [4]. By this method the soil densification can be achieved to significant depths by applying high energy impacts at the surface of the soils to ensure that the required characteristics are obtained. These impacts generate improvement from vertical and lateral displacement in the soil surrounding the impact point as well as from powerful shock waves occure in short duration which promote the re-arrangement of the soil particles into the denser configuration [9].

Dynamic Compaction is a cost effective method of ground improvement for sand densification. Furtherrmore, this method is appropriate for application to non-cohesive soils generally, the effectiveness of the this teqnique decreases as the cohesion of the soil increases $[14,5,13]$.

In this research, the field dynamic compaction (FDC) was used to improve the engineering properties of the gypseous soil near Bajii (160 km South of Mosul city) where an electrical power station is to be constructed.

\section{Dynamic Compaction}

Dynamic compaction consists of dropping a heavy mass repeatedly from a certain height to impact the ground. The subsoil improvement is a function of the applied energy which relates to the weight, hight of dropping, grid spacing and numbers of drops at each point as well as it depends on distribution of the drop locations, the soil strength, and the degree of the soil saturation[14].

Sketch (1) shows the principles of the this technique used in this study. The selection of weight (W) and drop height $(\mathrm{H})$ depends on the required depth (D) of improvement. Several studies investigated the effect of applied energy per drop on the depth of improvement and various relations were established $[11,8,15]$. 


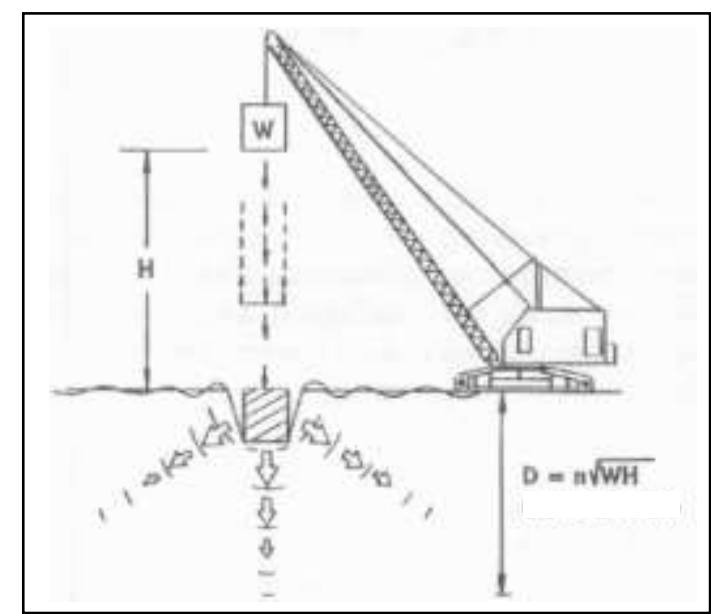

Sketch(1): Field Dynamic Compaction FDC

The most popular formula which is used in this study to predict the depth of improvement is Menard formula [2].

This formula is :

$$
D_{\max }=n(W H)^{0.5}
$$

where:

$D_{\max }=$ The maximum depth of improvement in meters,

$W=$ is the mass in tons

$H=$ is the fall height in meters, and

$\mathrm{n}=$ is an empirical constant.

Lukas [7] studied the factors which affect n-value. These factors are the total amount of applied energy, the type of soil, the presence of soil layers, and the efficiency of the drop. Van [16] suggested $(n=0.5)$ for clayey soils and $(n=0.65)$ for silty soils while, Mayne $[9,10]$ and Lukas [6] suggested n-vale ( 0.3-0.8) and (0.65-0.8) respectively for all soils. In this study a value of $(n=0.55)$ is used, and this value was obtained from the field test.

In this research the maximum thickness of the gypseous soil layer (D) that is to be improved is $(2.4 \mathrm{~m})$ which is located under tower $(\mathrm{F}-4)$ as shown in table (1). The FDC was executed by free dropping of reinforced concrete mass of 2.4 tons.

From equation (1):

$$
H_{\min }=\left(D_{\max }\right)^{2} / n^{2} . W \longrightarrow H_{\min }=(2.4)^{2} /\left(0.55^{2} * 2.4\right)=7.93 \approx 8.0 \mathrm{~m}
$$

The fall height of $(8.0 \mathrm{~m})$ was used in FDC under all towers foundations and a parametric study on soil below or near tower (F-4) was conducted using field penetration test (SPT) and the results are presented in table (2). 
No. 2

March 2014

Table (1): Thickness of soil layers from the bottom of foundation down to the sub-base materials (sand-gravel

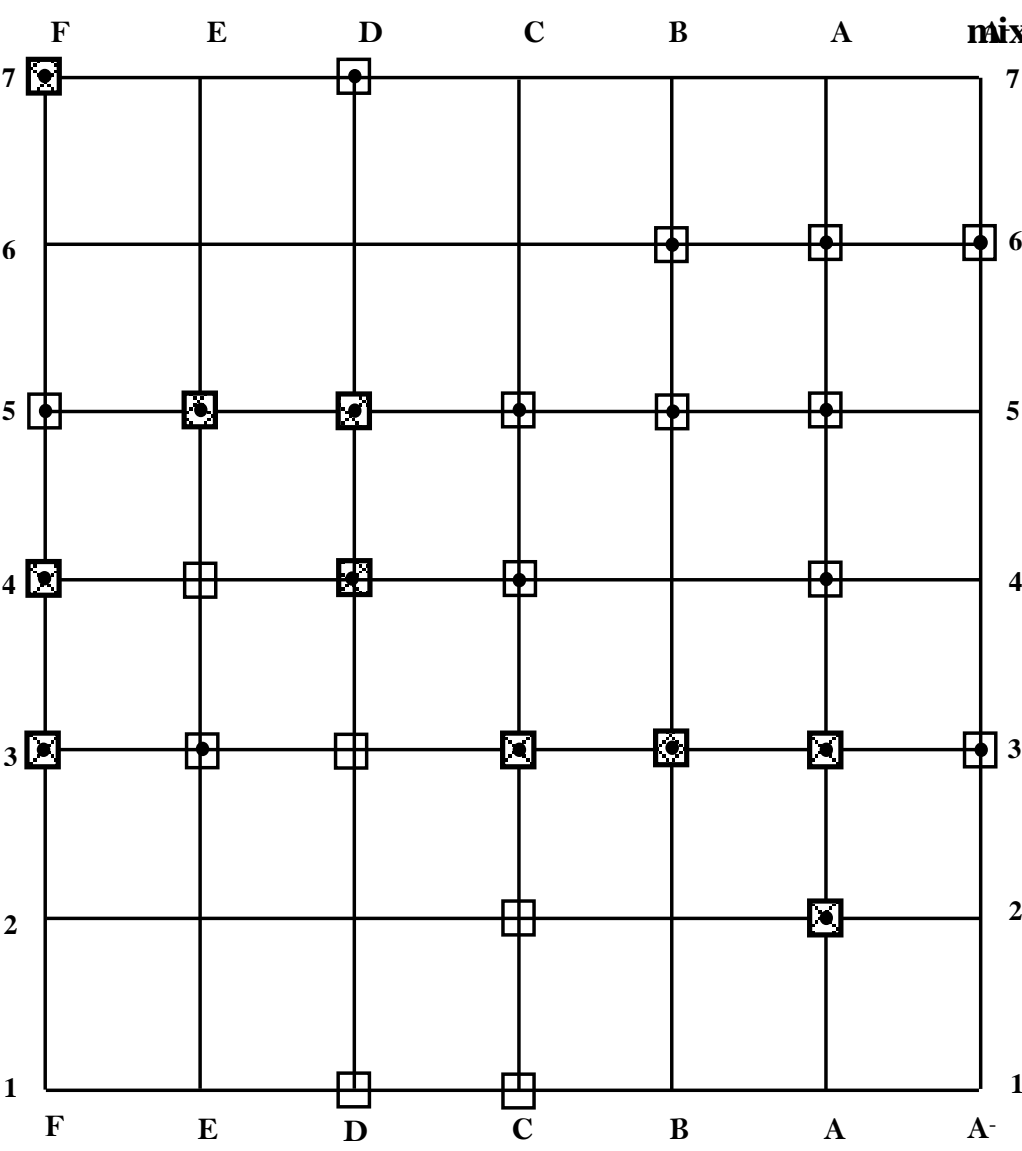
mixture)

Fig. (1): Site plane with location of towers' foundation
$\square$ Towers' Foundation
- B.H.
Selected Foundations

Table (2): Field Penetration Test (Parametric Study-F4)

\begin{tabular}{|c||c||c|c|c||}
\hline \multirow{2}{*}{$\begin{array}{c}\text { Dept } \\
\text { h } \\
(\mathbf{m})\end{array}$} & \multirow{2}{*}{ Before D.C } & \multicolumn{3}{|c|}{ After D.C } \\
\cline { 3 - 5 } & & $\begin{array}{c}\text { No. of } \\
\text { Drop = 1 }\end{array}$ & $\begin{array}{c}\text { No. of Drop } \\
=2\end{array}$ & $\begin{array}{c}\text { No. of Drop = } \\
\mathbf{3}\end{array}$ \\
\hline $\mathbf{0 . 5}$ & 11 & 19 & 20 & 21 \\
\hline 1.0 & 13 & 23 & 24 & - \\
\hline 1.5 & 17 & 27 & 27 & 28 \\
\hline 2.0 & 30 & 38 & - & 38 \\
\hline
\end{tabular}

\begin{tabular}{|c|c|}
\hline Location & $\begin{array}{l}\text { Thickness of } \\
\text { soil layers } \\
\text { (m) }\end{array}$ \\
\hline$* \mathbf{F}-7$ & 1.0 \\
\hline F-5 & 1.8 \\
\hline$* \mathrm{~F}-4$ & 2.4 \\
\hline *F-3 & 1.5 \\
\hline *E-5 & 1.4 \\
\hline E-3 & 1.4 \\
\hline D-7 & 0.5 \\
\hline$*$ D-5 & 1.1 \\
\hline$* \mathrm{D}-4$ & 2.1 \\
\hline C-5 & 0.6 \\
\hline C-4 & 0.6 \\
\hline$* \mathrm{C}-3$ & 1.4 \\
\hline B-6 & 1.6 \\
\hline B-5 & 0.6 \\
\hline$* \mathrm{~B}-3$ & 1.5 \\
\hline A-6 & 0.5 \\
\hline A-5 & 0.6 \\
\hline A-4 & 0.7 \\
\hline$* \mathbf{A}-3$ & 1.5 \\
\hline$* \mathbf{A}-2$ & 2.0 \\
\hline$A^{\prime}-6$ & 0.5 \\
\hline$A^{\prime}-3$ & 1.4 \\
\hline
\end{tabular}

*Selected

Foundations 


\section{Scope of the Study}

In order to achieve the objectives of this study, the following field and laboratory tests were performed:

\section{i. Field works :}

In the site twenty two boreholes (one borehole under each tower's foundation) were made down to the sub-base materials. Ten boreholes were selected for this study. The locations of all boreholes are shown in figure (1) where the shaded area represents the selected tower's foundation. Thickness of gypseous soil layers from the bottom of foundation level down to the sub-base materials are listed in table (1).

Figure (2) represents a typical $\log$ of boring while, figure (3) represents a typical soil profile at section F-F( see Fig.1).

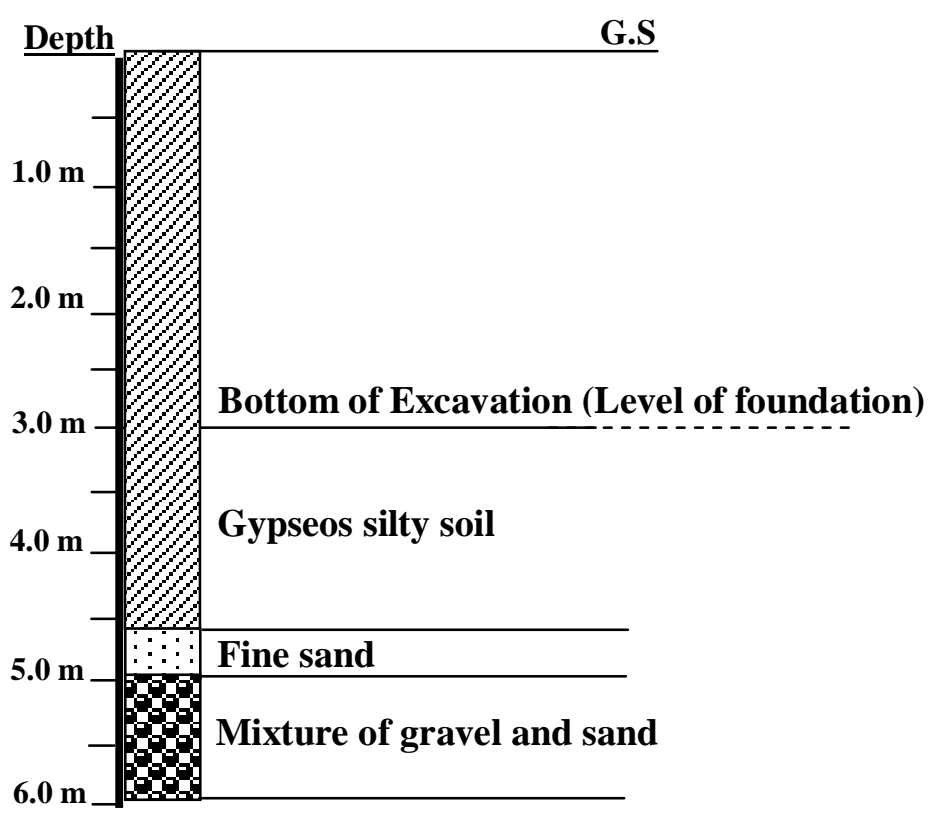

Fig.(2): Typical log of boring (B.H. A-2)

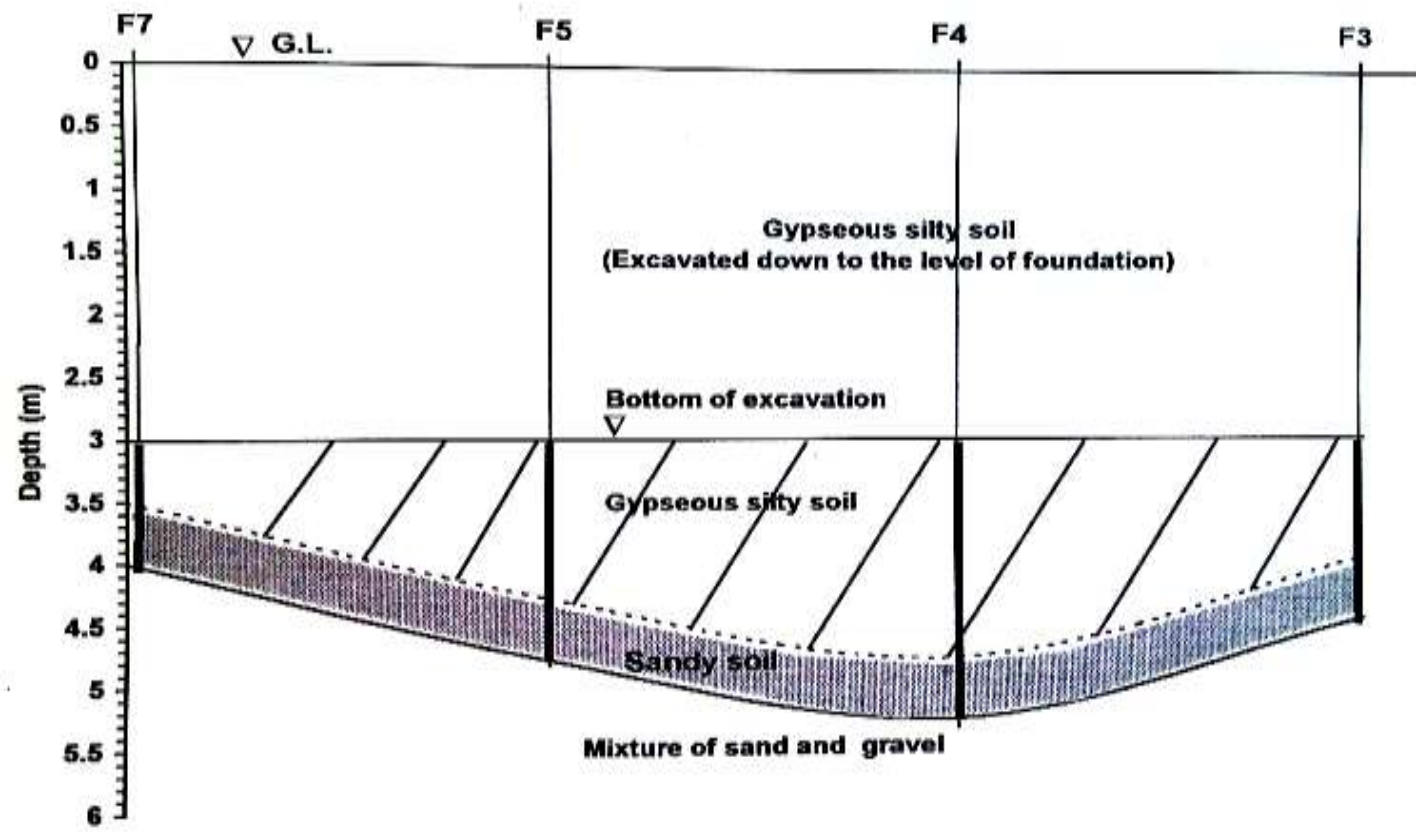

Fig. (3): Typical soil profile Section (F-F) 
Disturbed and undisturbed samples were obtaind from the selected boreholes before and after the Field Dynamic Compaction (FDC). All the samples were wrapped, sealed tightly in plastic bags, labeled and transported to soil mechanics laboratory / Engineerin CollegeUniversity of Mosul for the required tests.

The standared penetration test (SPT) was performd before and after the FDC and the results are presented in table (3). No water table was observed down to the investigated depths.

Table (3): Results of Field Penetration Test (SPT)

\begin{tabular}{|c|c|c|c|c|c|}
\hline \multirow[t]{2}{*}{ Location } & \multirow{2}{*}{$\begin{array}{l}\text { Depth } \\
\text { (m) }\end{array}$} & \multicolumn{2}{|c|}{ Before D.C } & \multicolumn{2}{|c|}{ After D.C } \\
\hline & & (*) No. of blows & Relative Density & (*) No. of blows & Relative Density \\
\hline \multirow[t]{4}{*}{ F-5 } & 0.5 & 11 & Medium & - & - \\
\hline & 1.0 & 13 & Medium & 23 & Medium \\
\hline & 1.5 & 19 & Medium & 27 & Medium \\
\hline & 1.8 & $>\mathbf{5 0}$ & $\begin{array}{c}\text { Very dense } \\
\text { (Gravel +Sand) }\end{array}$ & - & - \\
\hline F-4 & \multicolumn{5}{|c|}{ For parametric study (separately in table 2) } \\
\hline \multirow[t]{4}{*}{$\mathbf{F - 3}$} & 0.5 & 9 & Loose & 17 & Medium \\
\hline & 1.0 & 10 & Loose & - & - \\
\hline & 1.5 & 20 & Medium & 26 & Medium \\
\hline & 1.8 & $>\mathbf{5 0}$ & $\begin{array}{c}\text { Very dense } \\
\text { (Gravel +Sand) }\end{array}$ & - & - \\
\hline \multirow[t]{3}{*}{ E-5 } & 0.5 & 10 & Loose & - & - \\
\hline & 1.0 & 10 & Loose & 19 & Medium \\
\hline & 1.5 & 50 & $\begin{array}{c}\text { Very dense } \\
\text { (Gravel +Sand) }\end{array}$ & - & - \\
\hline \multirow[t]{3}{*}{ D-5 } & 0.5 & 9 & Loose & - & - \\
\hline & 1.0 & 11 & Medium & - & - \\
\hline & 1.5 & 26 & Medium & 31 & Dense \\
\hline \multirow[t]{3}{*}{ C-3 } & 0.5 & 15 & Medium & - & - \\
\hline & 1.0 & 12 & Medium & - & - \\
\hline & 1.5 & 30 & Dense & - & - \\
\hline \multirow[t]{3}{*}{ A-3 } & 0.5 & 18 & Medium & - & - \\
\hline & 1.0 & 30 & Dense & 35 & Dense \\
\hline & 1.5 & $>\mathbf{5 0}$ & $\begin{array}{c}\text { Very dense } \\
(\text { Gravel +Sand) }\end{array}$ & - & - \\
\hline
\end{tabular}

(*): The No. of blows are the average of the three values for each depth.

\section{ii. Labrotary Tests:}

In the labrotary, the properties of the soil before and after FDC were determined following the procedures given by the ASTM and the results are presented in tables (4-8) and figures (4$8)$. 
Al-Layla: Improving The Engineering Properties of The Gypseous Soil Using Dynamic

Table (4): Results of natural water content and dry unit weight

\begin{tabular}{|c|c|c|c|c|}
\hline \multirow[t]{2}{*}{ Location } & \multirow{2}{*}{$\begin{array}{l}\text { Depth } \\
\text { (m) }\end{array}$} & \multirow{2}{*}{$\begin{array}{c}\text { Natural } \\
\text { Water content }(w \%)\end{array}$} & \multicolumn{2}{|c|}{ Dry unit weight $\left(\gamma_{d} \mathrm{kN} / \mathrm{m}^{3}\right)$} \\
\hline & & & Before FDC & After FDC \\
\hline \multirow[t]{2}{*}{ F-7 } & 0.5 & 7.2 & 13.76 & 18.2 \\
\hline & 1.0 & 8.8 & 14.15 & 16.96 \\
\hline \multirow[t]{2}{*}{ F-4 } & 0.5 & 13.9 & 15.1 & 17.22 \\
\hline & 1.0 & 14.1 & 14.95 & $\mathbf{1 7 . 1}$ \\
\hline \multirow[t]{2}{*}{ F-3 } & 0.5 & 10.1 & 14.9 & $\mathbf{1 7 . 1 2}$ \\
\hline & 1.5 & 8.7 & 14.7 & 16.87 \\
\hline \multirow[t]{2}{*}{ E-5 } & 0.5 & 11.9 & 14.7 & 17.93 \\
\hline & 1.0 & 12.3 & 14.5 & 17.01 \\
\hline \multirow[t]{2}{*}{$\mathrm{C}-3$} & 0.5 & 15.1 & 14.1 & $\mathbf{1 7 . 8 1}$ \\
\hline & 1.0 & 14.8 & 14.3 & 16.99 \\
\hline \multirow[t]{3}{*}{ A-2 } & 0.5 & 13.5 & 15.2 & 18.21 \\
\hline & 1.0 & 14.1 & 14.7 & $\mathbf{1 7 . 7 5}$ \\
\hline & 1.5 & 14.2 & 13.8 & 16.73 \\
\hline
\end{tabular}

Table (5): Results of Atterberg Limits

\begin{tabular}{|c|c|c|c|c|c|}
\hline Location & Depth (m) & L.L (\%) & P.L (\%) & P.I (\%) & Classification \\
\hline \multirow[t]{2}{*}{ F-7 } & 0.5 & 25 & 19 & 6 & CL-ML \\
\hline & 1.0 & \multicolumn{4}{|c|}{ Non-plastic } \\
\hline \multirow[t]{4}{*}{ F-4 } & 0.5 & 23 & 19 & 4 & CL-ML \\
\hline & 1.0 & 26 & 18 & 8 & CL-ML \\
\hline & 1.5 & 25 & 18 & 7 & CL-ML \\
\hline & 2.0 & \multicolumn{4}{|c|}{ Non-plastic } \\
\hline \multirow[t]{3}{*}{ F-3 } & 0.5 & 29 & 16 & 13 & $\mathbf{C L}$ \\
\hline & 1.0 & \multicolumn{4}{|c|}{ Non-plastic } \\
\hline & 1.5 & \multicolumn{4}{|c|}{ Non-plastic } \\
\hline \multirow[t]{3}{*}{ E-5 } & 0.5 & 30 & 19 & 11 & $\mathbf{C L}$ \\
\hline & 1.0 & 27 & 17 & $\mathbf{1 0}$ & $\mathbf{C L}$ \\
\hline & 1.25 & \multicolumn{4}{|c|}{ Non-plastic } \\
\hline \multirow[t]{3}{*}{$\mathrm{C}-3$} & 0.5 & 27.5 & 16.5 & 11 & CL \\
\hline & $\mathbf{1 . 0}$ & 25 & 18 & 7 & CL-ML \\
\hline & 1.25 & \multicolumn{4}{|c|}{ Non-plastic } \\
\hline \multirow[t]{4}{*}{ A-2 } & 0.5 & 24-26 & 18-17 & $6-9$ & CL-ML \\
\hline & 1.0 & 25 & 17 & 8 & $\mathbf{C L}$ \\
\hline & 1.5 & 27 & 18 & 9 & $\mathbf{C L}$ \\
\hline & 2.0 & \multicolumn{4}{|c|}{ Non-plastic } \\
\hline
\end{tabular}


Table (6): Soil Chemical Properties

\begin{tabular}{|c|c|c|c|c|c|}
\hline Location & Depth (m) & T.S.S. (\%) & $\mathrm{SO}_{3}(\%)$ & Gypsum (\%) & O.M (\%) \\
\hline \multirow[t]{3}{*}{ F-7 } & 0.5 & 3.1 & 0.33 & 16.5-18.0 & 2.3 \\
\hline & 0.75 & 2.9 & 0.32 & 11.6-13.0 & 1.7 \\
\hline & 1.0 & 3.2 & 0.32 & 4.5-7.0 & 1.1 \\
\hline \multirow[t]{4}{*}{ F-4 } & 0.5 & $1.1-2.0$ & 0.23 & 14.0-16.3 & 3.2 \\
\hline & 1.0 & 1.2 & 0.43 & 9.5-13.0 & 1.7 \\
\hline & 1.5 & 2.3 & 0.44 & 6.5 & 2.7 \\
\hline & 2.0 & 2.6 & - & - & - \\
\hline \multirow[t]{3}{*}{ F-3 } & 0.5 & 3.2 & 0.36 & 11.5 & - \\
\hline & 1.0 & - & 0.41 & - & 2.1 \\
\hline & 1.5 & 3.3 & 0.29 & 1.8-2.1 & - \\
\hline \multirow[t]{3}{*}{ E-5 } & 0.5 & 3.1 & - & 16.2 & 3.1 \\
\hline & 1.0 & 2.3 & 0.31 & - & - \\
\hline & 1.25 & 4.1 & 0.28 & 5.5 & 1.1 \\
\hline \multirow[t]{2}{*}{ D-5 } & 0.5 & 1.2 & 0.41 & 16.0-18.0 & 2.3 \\
\hline & 1.0 & 3.1 & 0.35 & 11.5 & 2.1 \\
\hline \multirow[t]{3}{*}{$\mathrm{C}-3$} & 0.5 & 2.8 & 0.32 & $15.0-17.0$ & 1.6 \\
\hline & 1.0 & 4.0 & 0.35 & 10.0-11.6 & 1.2 \\
\hline & 1.25 & 3.1 & - & - & 0.9 \\
\hline \multirow[t]{3}{*}{ B-3 } & 0.5 & 2.3 & 0.35 & 18.6 & 3.2 \\
\hline & 1.0 & - & - & 7.2 & 2.1 \\
\hline & 1.5 & 2.2 & 0.31 & - & - \\
\hline \multirow[t]{4}{*}{ A-2 } & 0.5 & $2.0-3.8$ & 0.3 & 14.6-16.3 & 1.9 \\
\hline & 1.0 & 4.0 & - & 15.2-17.0 & 2.1 \\
\hline & 1.5 & - & 0.28 & 6.5 & 1.3 \\
\hline & 2.0 & 3.1 & - & 3.7 & - \\
\hline
\end{tabular}

Table (7): Results of direct shear test before and after field compaction

\begin{tabular}{|c|c|c|c|c|c|}
\hline Location & Depth(m) & \multicolumn{2}{|c|}{$\begin{array}{c}\text { Angle of internal friction } \\
\left(\phi^{-}\right), \text {degree }\end{array}$} & \multicolumn{2}{c|}{$\begin{array}{c}\text { Cohesion } \\
\left(\mathbf{c}^{-}\right), \mathbf{k N} / \mathbf{m}^{2}\end{array}$} \\
\cline { 3 - 6 } & & Before & After & Before & After \\
\hline F-4 & $\mathbf{0 . 5}$ & $\mathbf{3 2}$ & $\mathbf{3 6}$ & $\mathbf{0 . 0}$ & $\mathbf{0 . 0 5}$ \\
\hline E-5 & $\mathbf{1 . 0}$ & $\mathbf{3 3}$ & $\mathbf{3 6}$ & $\mathbf{0 . 0}$ & $\mathbf{0 . 0 6}$ \\
\hline D-5 & $\mathbf{1 . 5}$ & 34 & 36 & $\mathbf{0 . 0}$ & $\mathbf{0 . 0 5}$ \\
\hline A-2 & $\mathbf{2 . 0}$ & 34 & 35 & $\mathbf{0 . 0}$ & $\mathbf{0 . 0 4}$ \\
\hline
\end{tabular}


Al-Layla: Improving The Engineering Properties of The Gypseous Soil Using Dynamic

Table (8): Results of consolidation test before and after field compaction

\begin{tabular}{|c|c|c|c|c|c|}
\hline \multirow{2}{*}{ Location } & \multirow{2}{*}{$\begin{array}{c}\text { Depth } \\
(\mathbf{m})\end{array}$} & \multicolumn{2}{|c|}{ Void ratio $\left(\mathbf{e}_{\mathbf{o}}\right)$} & \multicolumn{2}{|c|}{$\left.\mathbf{c}_{\mathbf{c}}\right)$} \\
\cline { 3 - 6 } & Before & After & Before & After \\
\hline F-4 & $\mathbf{1 . 0}$ & $\mathbf{0 . 7 7}$ & $\mathbf{0 . 5 7}$ & $\mathbf{0 . 2 2}$ & $\mathbf{0 . 0 8 4}$ \\
\hline E-5 & $\mathbf{1 . 0}$ & $\mathbf{0 . 7 5 5}$ & $\mathbf{0 . 5 6 6}$ & $\mathbf{0 . 2 2}$ & $\mathbf{0 . 0 7 5}$ \\
\hline D-4 & $\mathbf{0 . 5}$ & $\mathbf{0 . 7 0 5}$ & $\mathbf{0 . 5 8 5}$ & $\mathbf{0 . 1 3}$ & $\mathbf{0 . 0 7 1}$ \\
\hline C-3 & $\mathbf{1 . 0}$ & $\mathbf{0 . 7 6}$ & $\mathbf{0 . 5 7}$ & $\mathbf{0 . 2 1}$ & $\mathbf{0 . 0 9}$ \\
\hline A-2 & $\mathbf{0 . 5}$ & $\mathbf{0 . 7 7 6}$ & $\mathbf{0 . 4 6 6}$ & $\mathbf{0 . 2 3}$ & $\mathbf{0 . 0 7}$ \\
\cline { 2 - 6 } & 1.5 & $\mathbf{0 . 8 4}$ & $\mathbf{0 . 6 0 3}$ & $\mathbf{0 . 2 4}$ & $\mathbf{0 . 1}$ \\
\hline
\end{tabular}

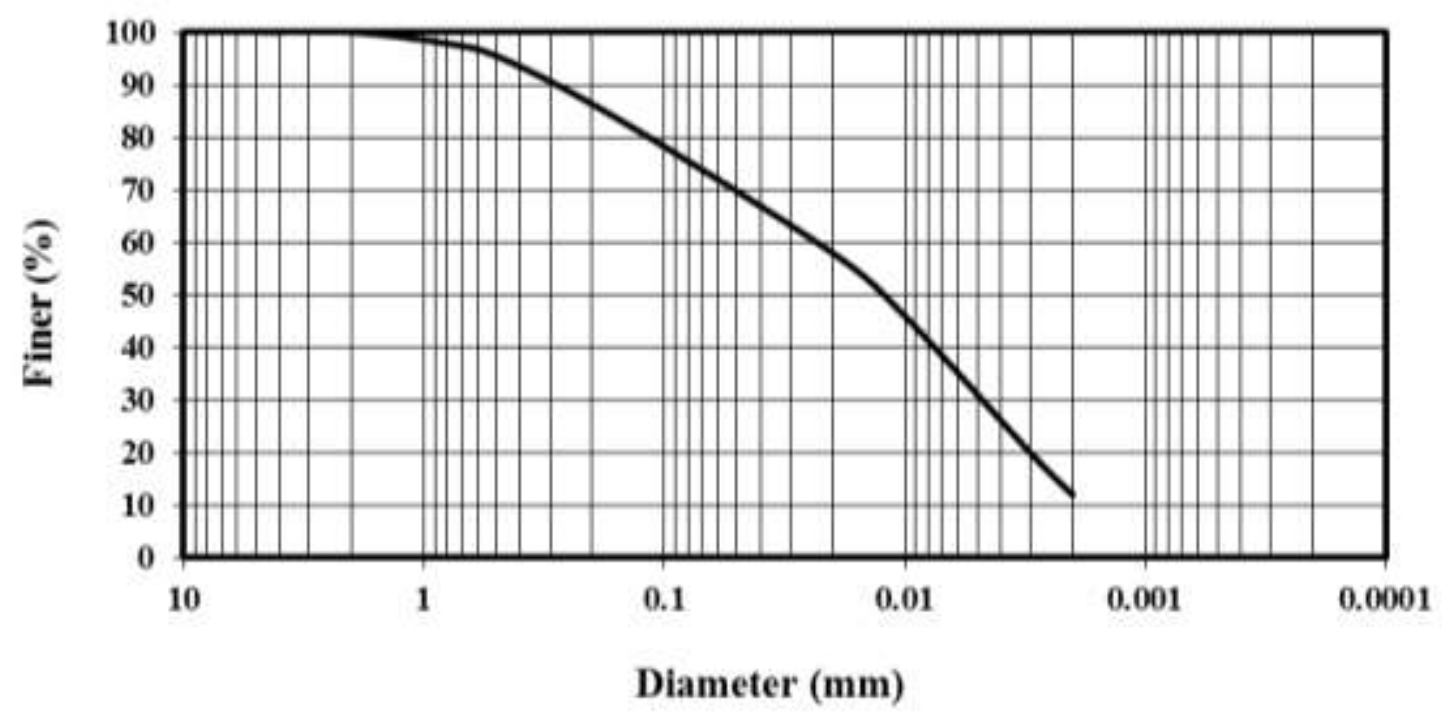

Fig.(3): Grain Size Distribution (B.H.C-3/D=0.5-1.0m)



Fig.(4): Grain Size Distribution (B.H.A-2 /D=1.0-1.5m) 
No. 2

March 2014
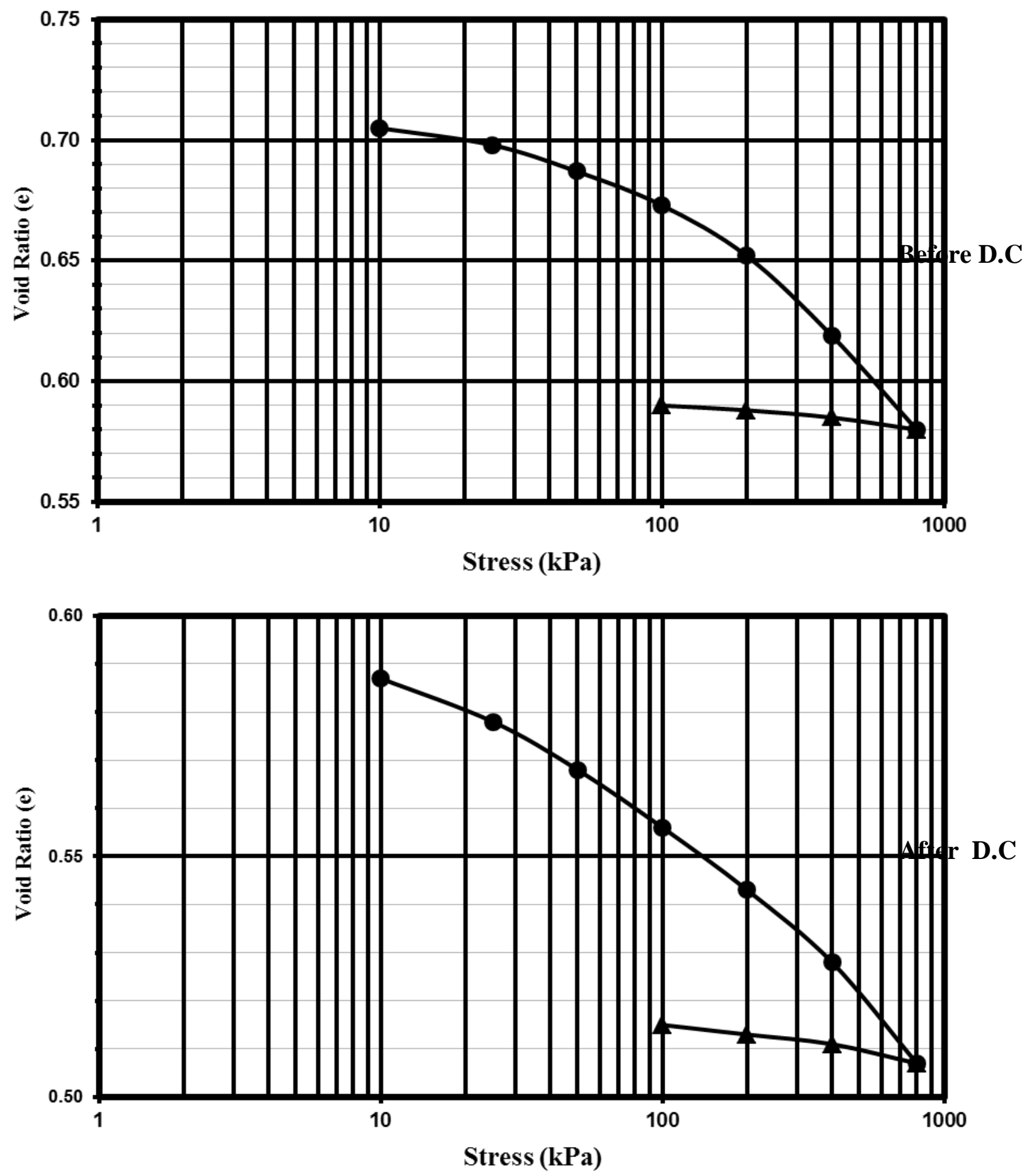

Fig. (6): Consolidation curve $\underline{\mathrm{D}-4 \text { / ( }(\mathrm{D}=0.5 \mathrm{~m})}$ before and after Dynamic Compaction 
Al-Layla: Improving The Engineering Properties of The Gypseous Soil Using Dynamic
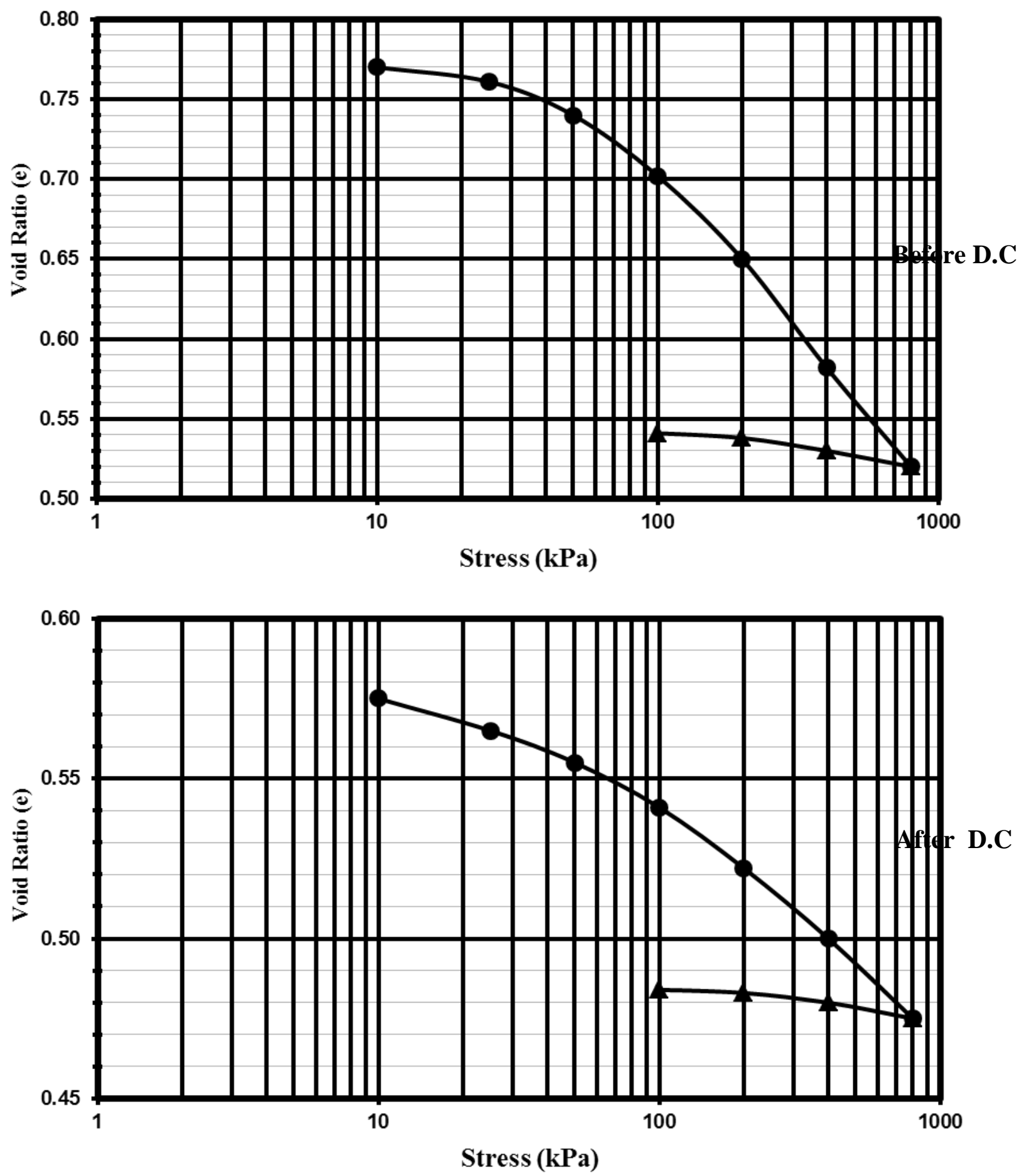

Fig. (7): Consolidation curve F-4 / $(\mathrm{D}=1.0 \mathrm{~m})$ before and after Dynamic Compaction 
No. 2

March 2014
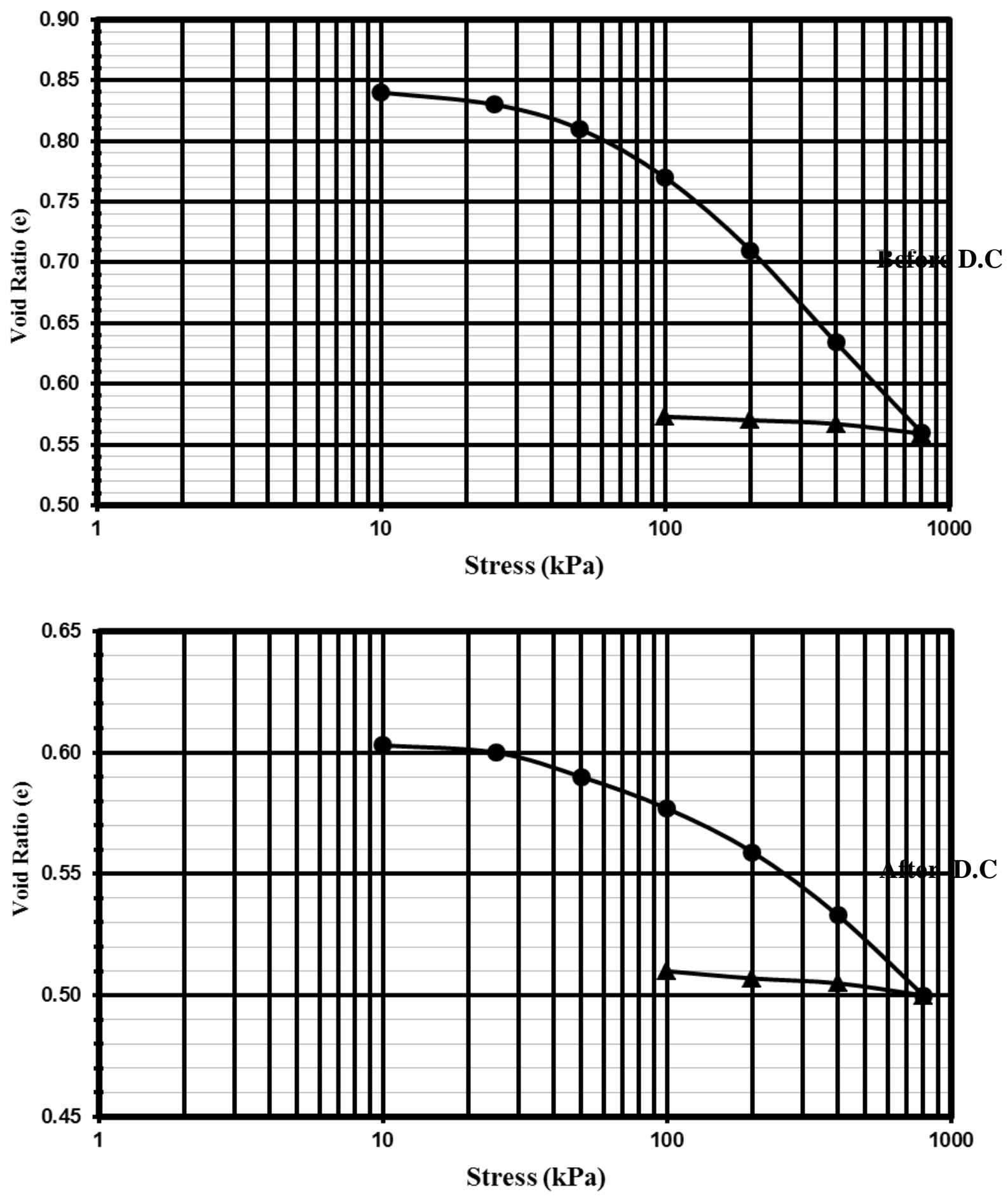

Fig. (8): Consolidation curve $\underline{A-2}$ / $(\mathrm{D}=1.5 \mathrm{~m})$ before and after Dynamic 


\section{Results and Discussion}

This study as stated before, was conducted on gypseous soil found in Bajii city (160 km South of Mosul city). Generally the soil is rather uniform, it consists of gypseous silty soil down to about $(0.5 \mathrm{~m})$ above the sub-base material, then changed to either silty sand or fine sand until reached the sub-base material as shown in figs $(2 \& 3)$. The thickness of soil layer above the sub-base material is shown in table (1). It varies from $(0.5 \mathrm{~m})$ to $(2.4 \mathrm{~m})$.

The results of field penetration test are shown in table (2) and according to these results most of the soil is either loose or medium in its relative density and with depth the soil becomes dense.

The Unified Classification System indicates that most of the soil is either CL or CLML. The dry unit weight varies from $\left(13.7 \mathrm{kN} / \mathrm{m}^{3}\right)$ to $\left(15.2 \mathrm{kN} / \mathrm{m}^{3}\right)$ before FDC and increased to $\left(16.7-18.2 \mathrm{kN} / \mathrm{m}^{3}\right)$ after FDC with an increases of (14-32\%).

The effective angle of internal friction $\left(\phi^{-}\right)$varies from $\left(32^{\circ}\right.$ to $\left.34^{\circ}\right)$ while, the effective cohesion intercept $\left(\mathrm{c}^{-}\right)$is zero. After FDC the internal friction $\left(\phi^{-}\right)$increased to (35 o- $36^{\circ}$ ).

The results of the consolidation test showed that the compression index $(\mathrm{Cc})$ varies from (0.13 to 0.24). According to these results, the expected settlement is about $(4.0 \mathrm{~cm})$ for each one meter thick of the soil. After FDC the compression index $(\mathrm{Cc})$ become $(0.07-0.1)$.

The results of this study indicate that about (60-80 \%) of the improvement was achieved from the first blow in loose to meduime soils, while about $(25 \%)$ of the improvement was reached in dense soils.

\section{CONCLUSION}

1. The Field Dynamic Compaction method (FDC) is very effective method to improve the engineering properties of gypseous soil. It increase the unit weight and soil strength while, the soil compressibility decreases.

2. The Menard formula can be used effectively in gypseous soil with avalue of $(n=0.55)$.

3. The results of this study indicates that about (60-80\%) of the improvement was achieved from the first blow in loose to meduime soils, while about $(25 \%)$ of the improvement was reached in dense soils.

\section{References}

1. Al-Zahrani, R. and Rouaiguia, A., (2002), "Simulation of Soil Dynamic Compaction", The $6^{\text {th }}$ Saudi Engineering Conference, KFUPM, Dhahran, Vol.3, pp.223-232

2. Arslan, H., Baykal, G. and Ertas, O., (1997), "Influence of tamper weight shape on dynamic compaction", ASCE, Ground Improvement, No.2, American Society of Civil Engineers, New York, USA., pp. 61-66.

3. Ghassemi, A., Pak, A. and Shahir, H., (2009), "A Numerical Tool for Design od Dynamic Compaction Treatment in Dry and Moist Sands",Iranian Journal of Science \& Technology, Transaction B, Engineering, Vol. 33, No. B4, pp. 313-326.

4. Khattab, S., Ibrahim, K. and Khalel, A.A., (2013)," Improvement of Soft Soil Properties Using Dynamic Compaction with Stone Columns: Case Study (ALMualla Site-Yeman)", 
1 st international conference for geotechnical engineering and transportation engineering ICGTE, Baghdad, Iraq.

5. Kyle, M.R. and Jihyoung, K., (2010), "Dynamic Compaction of Collapsible oils Based on U.S. Case Histories", Journal of Geotechnical and Geo-environmental Engineering, Volume 136, Issue 9, pp. 1178-1186.

6. Lukas, R. G., (1984), "Densification of loose deposits by pounding", Journal of the Geotechnical Engineering Division, ASCE, 106, No. GT4, pp. 435-446.

7. Lukas, R. G., (1995),"Geotechnical Engineering Circular No.1-Dynamic compaction", FHWA-SA-95-037.

8. Luongo, V., (1992), "Dynamic compaction. Predicting depth of improvement", GSP, Vol. 2, No. 30, pp. 927-939.

9. Mayne P. W., (1984), "Ground improvement by dynamic compaction",In Civil Engineering Practice: Geotechnical Ocean Engineering, Vol, 3, Chapter 11, Technomic Publishing, N.J., pp. 405-442.

10. Mayne, P. W., Jones, J. S. \& Dumas, J. C. ,(1984),"Ground response to dynamic compaction", ASCE 110, GT6, pp. 757-773.

11. Menard, L. \& Broise, Y., (1975), "Theorical and practical aspects of dynamic consolidation", Geotechnique, Vol. 5, No. 1, pp. 3-16.

12. Mostafa, KH,(2010), "Numerival Modeling of Dynamic Compaction Cohesive Soil", $\mathrm{Ph}$.D. thesis, University of Akron, USA.

13. Nashed, R., Thevanayagam, S., and Martin, G., (2006)," Simulation of Dynamic Compaction Processes in Saturated Silty Soils", American Society of Civil Engineers ASCE, pp. 1-6.

14. Satyapriya, C.K., and Gallagher, P.E., (2000)," Dynamic Compaction of Surface Mine Spoils to Limit Settlements Within Commercial Development", Construction and Controlling Compaction of Earth Fills, ASTM STP 1384, Shanki, D.W., Rademacher, K.R. and Talbot, J.R., Journal of the Geotechnical Engineering Division, USA.

15. Scolombe, B. C., (2004), "Dynamic compaction. Ground improvement", Moseley, M.P., Ed., pp. 93-118.

16. Van,I.W.(1989), "Soil Improvement Techniques and Their Evolution",Balkema, Rotterdam.

The work was carried out at the college of Engineering. University of Mosul 